\title{
VIVÊNCIAS NA REDE DE SAÚDE E PSICOLOGIA: INTERAÇÕES DA RESIDÊNCIA MULTIPROFISSIONAL EM SAÚDE DA FAMÍLIA
}

EXPERIENCES IN HEALTH NETWORK AND PSYCHOLOGY: INTERACTIONS OF THE MULTIPROFESSIONAL RESIDENCY IN FAMILY HEALTH

VIVENCIAS EN LA RED DE SALUD Y PSICOLOGÍA: INTERACCIONES DE LA RESIDENCIA MULTIPROFESIONAL EN SALUD DE LA FAMILIA

Ana Karina de Sousa Gadelha Amanda Colares Bezerra ${ }^{1}$ George Luiz Costa de Paula 3

Paulo Cesar de Moura Luz ${ }^{4}$

Palavras-chave: Recursos Humanos em Saúde; Saúde da Família; Psicologia.

Palabras clave: Recursos Humanos en Salud; Salud de la Familia; Psicología.

Submetido: 28/10/2017

Aprovado: 07/04/2018

Autor(a) para Correspondência: Ana Karina de Sousa Gadelha End: Av. John Sanford, 1320, Junco CEP: 62030-240, Sobral-CE E-mail: Karina_gadelha@yahoo.com.br

\section{RESUMO}

Este artigo consiste em um relato da vivência obrigatória em rede do programa de Residência Multiprofissional em Saúde da Família da Escola de Formação em Saúde da Família Visconde de Sabóia (RMSF/EFSFVS), em Sobral-CE. Assim, o objetivo é apresentar, refletir e discutir os serviços vivenciados, para analisar suas idiossincrasias e indicar como o contato com tais serviços pode contribuir com as articulações em rede relativas à atuação da Psicologia na Estratégia Saúde da Família (ESF), como categoria profissional e equipe multiprofissional. A vivência obrigatória está prevista na proposta pedagógica da RMSF/EFSFVS, com carga horária de 80 horas, distribuídas no primeiro ano de residência. A experiencia apresentada neste relato foi realizada no periodo de julho a dezembro de 2015, em 6 serviços municipais de saúde. 0 relato ilustra as impressões e afetações dos residentes em relação aos serviços vivenciados, bem como as contribuições da vivência obrigatória para estreitamento de vínculos entre serviços, melhorando a resolutividade dos problemas enfrentados no cotidiano da Atenção Primária à Saúde (APS).

\footnotetext{
1. Psicóloga. Preceptora de núcleo no programa de Residência Multiprofissional em Saúde da Família (RMSF). Sobral (CE), Brasil. E-mail: karina_gadelha@yahoo.com.br

2. Psicóloga. Residente no programa de RMSF. Sobral (CE), Brasil. E-mail: amandacolaresb@gmail.com

3. Psicólogo. Residente no programa de RMSF. Sobral (CE), Brasil. E-mail: luiz.george@ymail.com

4. Psicólogo. Residente no programa de RMSF. Sobral (CE), Brasil. E-mail: paulo.cesarluz@hotmail.com
} 


\section{ABSTRACT}

This article consists in a report of the mandatory experience in a network of the Brazilian program of Multiprofessional Residency in Family Health of the Family Health Education School 'Visconde de Sabóia' (RMSF/EFSFVS), in Sobral, Ceará, Brazil. Thus, the aim is presenting, thinking through, and discussing the services experienced, in order to analyze their idiosyncrasies and indicate how the contact with such services can contribute to the network interconnections related to Psychology working in the Family Health Strategy (FHS), both as a professional category and a multiprofessional team. The mandatory experience is provided for in the pedagogical proposal of the RMSF/EFSFVS, with a 80-hour workload, distributed in the first year of residency. The experience presented in this report took place within the period from July to December 2015, in 6 municipal health services. The report depicts the residents' impressions and affections regarding the services experienced, as well as the contributions of the mandatory experience to narrow the relations between services, improving the problem-solving performance in the daily routine of the Primary Health Care $(P H C)$.

\section{RESUMEN}

Este artículo consiste en un informe de la vivencia obligatoria en una red del programa brasileño de Residencia Multiprofesional en Salud de la Familia de la Escuela de Formación en Salud de la Familia "Visconde de Sabóia" (RMSF/EFSFVS), en Sobral, Ceará, Brasil. Así, el objetivo es presentar, reflejar y discutir los servicios vivenciados, para analizar sus idiosincrasias e indicar cómo el contacto con dichos servicios puede contribuir a las articulaciones en red relativas a la actuación de la Psicología en la Estrategia Salud de la Familia (ESF), como categoría profesional y equipo multiprofesional. La vivencia obligatoria está prevista en la propuesta pedagógica de la RMSF/EFSFVS, con una carga de trabajo de 80 horas, distribuidas en el primer año de residencia. La experiencia presentada en este informe se realizó en el periodo de julio a diciembre de 2015, en 6 servicios municipales de salud. El informe ilustra las impresiones y afectaciones de los residentes con respecto a los servicios experimentados, asícomo las contribuciones de la vivencia obligatoria para estrechar relaciones entre servicios, mejorando el desempeño de la resolución de problemas en el cotidiano de la atención primaria de salud (APS).

\section{INTRODUÇÃO}

Sobral, município localizado no norte do Ceará, caracteriza-se pela existência de um Sistema Saúde Escola, que busca contemplar as diretrizes propostas pela Política Nacional de Educação Permanente em Saúde (PNEPS). Esse sistema é compreendido como um modelo ampliado de organização dos processos de ensino-aprendizagem integrado à rede local de saúde, tendo na Secretaria Municipal de Saúde e na Escola de Formação em Saúde da Família Visconde de Sabóia (EFSFVS) seus representantes institucionais.

Viabilizando a proposta de converter toda a rede de serviços de saúde do município em espaços de educação contextualizada, a EFSFVS assumiu localmente o desafio de subsidiar, no campo da saúde pública, as novas políticas e práticas decorrentes das profundas mudanças implantadas em Sobral a partir de 1997 - quando se estabeleceu um novo projeto político-administrativo municipal ${ }^{1}$.

0 programa de Residência Multiprofissional em Saúde da Família (RMSF), efetivado pela EFSFVS em parceria com a Universidade Estadual Vale do Acaraú (UVA) desde 1999, consiste em uma pós-graduação com caráter de residência e tem por objetivos qualificar a atuação no setor saúde com base em uma mudança de mentalidade não necessariamente proveniente da apreensão de conteúdos - comum em cursos nesse nível de formação ${ }^{2}$.

Caracterizado como um programa que adota 0 processo de trabalho tendo como princípio e finalidade os processos de formação, a RMSF adota igualmente uma pedagogia dialógica e problematizadora. A educação/formação em serviço proposta para os programas de Residência Multiprofissional em Saúde (RMS) avança quando consegue conectar-se à prática dos profissionais, com base no encontro entre as pessoas, no diálogo e na transformação permanente de si e do mundo ${ }^{3}$.

0 marco teórico-metodológico da RMSF/EFSFVS advém da promoção da saúde, da educação permanente, da educação popular e da educação por competências ${ }^{2}$, cada uma delas articulada em uma perspectiva de aprendizagem significativa, que considera os afetos e sentidos envolvidos no processo de educação. 0 modelo pedagógico do programa de RMSF se distribui entre: a) vivências teóricoconceituais, atreladas aos ciclos temáticos; b) vivências nos territórios, articulando a formação em serviço; e c) vivências de produção científica, 
concomitante a esses processos e vivências de extensão ${ }^{2}$.

Esta última, como objeto principal deste texto, caracteriza-se como um rico momento que intensifica e aprimora o fazer profissional pertinente a cada categoria integrante da RMSF/EFSFVS, a partir da busca de conhecimentos e experiências relevantes, sempre visando a contribuir para aumentar a efetividade das praticas e dos saberes ${ }^{2}$.

0 objetivo deste relato de vivência é apresentar reflexões sobre a vivência da categoria de Psicologia na RMSF/EFSFVS (turma número 12) e suas contribuições para as articulações na rede municipal de saúde.

\section{METODOLOGIA}

Este artigo consiste em um relato de experiência que apresenta as vivências de extensão da RMSF/ EFSFVS, sob a perspectiva da categoria de Psicologia (turma número 12), composta por 3 psicólogos residentes e 1 psicóloga preceptora. As vivências obrigatórias de extensão têm carga horária de 80 horas, distribuídas pelos serviços de saúde do município afins à categoria, sendo a carga horária mínima de 12 horas por serviço.

A preceptoria, em acordo com os psicólogos residentes, elegeu 6 serviços a vivenciar, considerando a relevância para a formação, bem como o estreitamento de laços na rede de saúde. Optou-se por vivenciar os seguintes serviços: a) Centro de Atenção Psicossocial Geral (CAPS Geral) - 16 horas; b) Centro de Atenção Psicossocial Álcool e Drogas (CAPS AD) - 16 horas; c) Centro de Orientação e Apoio Sorológico (Coas) - 12 horas; d) Centro de Referência em Saúde do Trabalhador (Cerest) - 12 horas; e) Estratégia Trevo de Quatro Folhas - 12 horas; e f) Hospital Dr. Estevam Ponte - 12 horas.

0 período de vivências compreendeu o período de julho a dezembro de 2015. Todos os momentos foram articulados e agendados previamente por meio de mediação realizada pela preceptora de núcleo da RMSF/EFSFVS. As vivências foram de observação/ intervenção e não causaram nenhum prejuízo ou constrangimento aos envolvidos, sendo conduzidas de modo íntegro e respeitoso.

\section{RESULTADOS E DISCUSSÃO}

0s resultados apresentados a seguir foram organizados por tópico, com a descrição das

\section{A implantação da \\ RAISM contribuiu com a transformação do lugar social das pessoas com transtorno mental...}

atividades e os contextos experimentados pelos psicólogos residentes, bem como a problematização e reflexão sobre o processo. Consideramos, para fins da organização deste relato, a Rede de Atenção Integral à Saúde Mental (RAISM) um só tópico agrupando 3 serviços vivenciados: CAPS Geral, CAPS Ad e Unidade de Internação Psiquiátrica em Hospital Geral (UIPHG) do Hospital Dr. Estevam Ponte. Em seguida, trazemos os tópicos Estratégia Trevo de Quatro Folhas, Coas e Cerest.

\section{Rede de Atenção Integral à Saúde Mental}

A RAISM surgiu no contexto da reforma psiquiátrica em Sobral, como estratégia substitutiva ao modelo psiquiátrico hospitalocêntrico que imperava na assistência ao sujeito em sofrimento ou adoecimento mental - com caráter manicomial da Casa de Repouso Guararapes. Essa instituição foi criada em 1974 e consolidou-se como referência regional na assistência psiquiátrica, permanecendo até a data de 10 de julho de 2000, quando foi descredenciada pela Secretaria de Saúde e Ação Social de Sobral, por meio da Portaria n. 113, devido a uma série de denúncias de maustratos, abusos e irregularidades ${ }^{4,5}$.

A implantação da RAISM contribuiu com a transformação do lugar social das pessoas com transtorno mental, uma vez que a rede se orienta por uma atuação humanizada, integral e territorial ${ }^{4}$, além de ser basilar para a política de saúde mental de Sobral.

Dentre os dispositivos que compõem a RAISM foi possivel estabelecer um contato vivencial com o CAPS Geral II, CAPS AD e a UIPHG do Hospital Dr. Estevam Ponte.

0 CAPS Geral de Sobral é do tipo II, que, conforme a Portaria n. $336 / \mathrm{GM}$ de $2002^{6}$ assiste territórios com população entre 70.000 e 200.000 habitantes, trabalha com várias equipes e funciona das 8:00 às 18:00, de segunda a sexta-feira. Trata-se de um dos serviços da atenção secundária à saúde imprescindível 
para o atendimento à demanda de saúde mental do município. Em seu projeto, ressaltam-se como principais características a integração com outros níveis de atenção, integração a sistemas de política social, acessibilidade, multiplicidade de funções e técnicas, prática multiprofissional e interdisciplinar, educação permanente e redução crítica da hierarquia assistente/assistido. Com isso, o CAPS busca trabalhar o protagonismo e a (co)responsabilização dos usuários no que diz respeito ao seu tratamento, promovendo maior autonomia e transformando a clínica tradicional ${ }^{4}$.

Foram vivenciados quatro turnos de atividades nesse serviço. 0 primeiro contato consistiu na apresentação do serviço, contextualizando-o a partir da RAISM do município, a importância social e comunitária, a constituição das equipes multiprofissionais e a integração e atuação multiprofissional, bem como o fluxograma do serviço e a articulação com a rede.

Outra atividade vivenciada foi o acolhimento, realizado por técnicos designados para a atividade no dia, objetivando a escuta inicial e uma triagem institucional. Durante o período de vivência, observamos que existem diversas formas de acolhimento, variando de acordo com o manejo/a metodologia do técnico do acolhimento. Um dos tipos vivenciados foi o acolhimento coletivo, em que é realizado um convite a todos os usuários que se encontram no serviço naquele turno. Inicialmente, o profissional de referência faz uma breve introdução, explicando aos usuários como funciona o momento, acordando algumas regras (respeitar os colegas e a fala do outro, não dar conselho, falar de si etc.) e faz uma escuta inicial de cada usuário, coletando informações relevantes para a condução do caso. Depois disso, os usuários são convidados a deixar a sala de acolhimento e aguardar na sala de espera, enquanto o técnico discute os casos do acolhimento com o médico psiquiatra para adotar os devidos encaminhamentos. Finalmente, retorna com o coletivo de usuários e acompanhantes para as devolutivas de cada caso individualmente e orientações gerais.

Observa-se que, embora seja inovador, esse espaço poderia ser potencializado, podendo a equipe incrementar metodologias ativas para promover maior interação ao invés de agrupar os usuários e escutálos individualmente.

As outras atividades acompanhadas no serviço foram o grupo de lazer e o grupo de práticas corporais. São atividades realizadas por técnicos, onde a maioria

\section{0 acolhimento sempre é realizado por profissionais de referência designados por turno.}

dos participantes são usuários intensivos do serviço. As duas atividades se assemelham, pois exercem um importante papel de desconstrução de uma lógica manicomial, ao passo que também objetivam a ocupação e/ou a utilização de espaços públicos pelos usuários do serviço, que muitas vezes se afastam e/ ou são afastados desses espaços sociais, como praças públicas, teatro, museu, dentre outros.

Durante a vivência, também destinamos quatro turnos voltados a CAPS AD. 0 primeiro deles consistiu na apresentação do serviço, contemplando seu espaço físico, profissionais e serviços ofertados. Conforme relato da coordenadora do serviço, o CAPS AD de Sobral foi criado em outubro de 2002, atendendo a população do município e cidades vizinhas. Caracteriza-se como porta aberta para pessoas com transtornos decorrentes do uso de sustâncias psicoativas.

0 serviço realiza atendimentos individuais, grupais, visitas domiciliares, apoio matricial, oficinas terapêuticas, atendimento aos familiares, dentre outros. Conta com equipe multiprofissional composta por assistente social, enfermeiro, médico clínico, psiquiatra, psicólogo, terapeuta ocupacional, técnico de enfermagem e oficineiro.

0 acolhimento sempre é realizado por profissionais de referência designados por turno; diferentemente do acolhimento realizado pelo CAPS Geral, ele tem uma forma muito particular de procedimento. É realizado individualmente, com acompanhamento de um familiar. Após a escuta inicial pelo técnico de referência do dia, o caso é encaminhado para a renovação de receita de medicamento e agendado para médico clínico, psiquiatra, psicólogo ou grupo do serviço.

Durante o turno de acolhimento vivenciado foi possível perceber uma especificidade do serviço: o grande número de pessoas que buscam o serviço após as recaídas e abandono do tratamento por um período significativo de tempo.

0 grupo de lazer vivenciado foi um piquenique na 
margem esquerda do Rio Acaraú, regado a músicas e conversas sobre o papel de cada um na sociedade. Já nosso último turno de vivência consistiu em uma roda de conversa sobre a participação dos usuários nas reivindicações de melhoria para o serviço, pois naquele dia a atividade que seria realizada deixou de ocorrer por falta de material, além de outras limitações levantadas pelo grupo.

Esses dois momentos constituíram uma experiência muito rica, de muitas trocas e empoderamento e colaboram para alcançar um dos grandes objetivos do serviço, que é contribuir para o resgate da cidadania e da inclusão social das pessoas com transtornos decorrentes do uso e da dependência de substâncias psicoativas.

A UIPHG funciona no Hospital Geral Dr. Estevam Ponte, em Sobral. Trata-se de uma instituição privada, conveniada ao Sistema Único de Saúde (SUS), referência para a macro e microrregião estadual em que o município se encontra, contando atualmente com 17 leitos e mais 5 leitos flutuantes na clínica. A unidade é referência para urgência, emergência, internação e pronto atendimento psiquiátrico ${ }^{7}$.

Instituída no ano 2000, após o descredenciamento da Casa de Repouso Guararapes, a unidade tem por objetivo garantir a retaguarda de internação às pessoas que apresentem crises de maior gravidade. A regulação das internações psiquiátricas da UIPHG é realizada pelos serviços extra-hospitalares CAPS, CAPS AD e Centro de Especialidades Médicas (CEM), depois de esgotadas outras possibilidades de tratamento ${ }^{7}$.

A UIPHG se insere no contexto da Reforma Psiquiátrica brasileira, que preconiza a progressiva adoção de serviços substitutivos de saúde mental de base territorial, que contemplem a atenção psicossocial. Assim, os objetivos específicos do serviço se referem ao pronto atendimento a usuários em situação aguda de sofrimento mental, a redução do tempo e do estigma da internação psiquiátrica e a recondução do usuário a seu meio social ${ }^{8}$.

Para nós, a visita à UIPHG foi de significativa relevância, tanto profissional como pessoal. Ao longo da carga horária de 12 horas, realizamos diferentes atividades com usuários e familiares, abordando questões reflexivo-vivenciais. Nosso contato com o ambiente, a equipe de trabalho e os usuários gerou em nós efeitos desmistificantes, em especial quando trazemos uma bagagem social carregada de preconceito para com os sujeitos que lá se encontram. Consideramos que o simples fato de poder refletir

\section{...as músicas mobilizaram falas e afetos, mesmo no silêncio de alguns...}

sobre essas questões já foi de fundamental importância dentro dos objetivos da vivência.

Mesmo com pouco tempo, permitimo-nos realizar algumas atividades que pudessem suscitar reflexões junto aos usuários e familiares. Ao proporcionar espaços de escuta, percebemos sofrimentos, desejos, receios e alegrias, que, inseridos no contexto do momento, expressam de modo singular a história pessoal de cada sujeito. Até para nós, que estávamos há poucos dias no serviço, mostrou-se expressivo o contato com essas realidades - que mobilizou e desconstruiu muitas de nossas concepções anteriores.

Uma de nossas formas de estabelecer vínculos e afetos se deu a partir de uma intervenção que não trazia grandes pretensões, mas terminou por se mostrar um poderoso instrumento de escuta e conhecimento da realidade dos usuários da unidade. Tratou-se de uma intervenção musical, realizada com um violão, músicas e convite ao uso da palavra.

Organizamos uma roda com cadeiras e deixamos em aberto o convite para aqueles que se sentissem à vontade para integrar aquele espaço. Aos poucos, alguns se aproximavam, sentavam e contavam suas histórias. A metodologia era simples: o usuário escolhia uma música que gostava, nós tocávamos e cantávamos a música juntos e, em seguida, abríamos a conversa aproveitando a escolha do usuário para convidá-lo a falar sobre sua história de vida ou outras questões.

Percebemos o quanto as músicas mobilizaram falas e afetos, mesmo no silêncio de alguns, uma vez que a recordação de fatos e memórias do passado e a relação daquela música com o momento presente se mostraram uma nítida oportunidade terapêutica. Ressaltamos, aqui, o modo como a arte é capaz de elaborar e dizer o que não se diz, de subverter ordens e apontar outros caminhos, de trazer à tona verdades e compreensões até então imperceptíveis aos próprios usuários.

Consideramos que essa intervenção foi a forma de escapar a uma lógica de tratamento que, por vezes, acaba traduzindo-se em uma readaptação do indivíduo 
à engrenagem doente ${ }^{9}$. Assim, para que as bases plantadas pela Reforma Psiquiátrica não se apresentem como mero rearranjo de instituições e práticas tradicionais ${ }^{10}$, intervindo diretamente nos cenários de ações e provocando questionamentos políticos, faz-se necessário que as atividades realizadas sempre fomentem a autonomia dos sujeitos.

Sabemos que apenas a saída da instituição asilar e a oposição à lógica hospitalocêntrica não significam que acabamos com os manicômios que nos habitam, pois ainda há alguns aprisionamentos que nos impedem de inventar e de resistir, inviabilizando a criação de novas formas de lidar com a loucura ${ }^{11}$.

Perspectivas como essa nos levam a atentar para a necessária e contínua criação de linhas de fuga que resistam às capturas do cotidiano de uma atividade profissional acrítica, a saber: a) burocratização do cuidado; b) precarização das condições de trabalho; e c) economia de tempo em detrimento da otimização da produtividade.

\section{Estratégia Trevo de Quatro Folhas}

A Estratégia Trevo de Quatro Folhas foi implantada em Sobral em 2001, surgindo a partir da necessidade de reorganizar a atenção materno-infantil no município, quando se identificou, a partir da análise de óbitos materno-infantis, diversos problemas relacionados às condições de vida das mulheres durante a gestação e nos períodos iniciais do cuidado com os filhos, sobressaindo-se a ausência do apoio social nessa fase do ciclo de vida da mulher ${ }^{12}$.

A estratégia se divide em 4 etapas: a) assistência ao pré-natal; b) parto/puerpério; c) nascimento; e d) acompanhamento até os 2 anos de vida do bebê. Constitui-se como política pública municipal e é desenvolvida com o apoio da sociedade civil e de pessoas jurídicas. Outra característica importante é que se encontra ligada à comunidade tanto pelo atendimento como pelo papel imprescindível das Mães Sociais ${ }^{12}$ - pessoas da comunidade capacitadas para acompanhar gestantes e puérperas em situação de vulnerabilidade social.

0 serviço conta com uma atuação multiprofissional e interdisciplinar e realiza outras ações, como: a) acompanhamento às gestantes usuárias de drogas; b) identificação de recém-nascidos de risco; c) internamento e alta de gestantes e crianças e repasse diário dessas informações aos Centros de Saúde da Família (CSF); d) operacionalização do Comitê de Prevenção da Mortalidade Materna, Perinatal e

\section{o SUS tem como um de seus objetivos cuidar integralmente da saúde da população...}

Infantil (CPMMPI) de Sobral; e e) doação de Kit Gestante ${ }^{12}$.

Nesse serviço, acompanhamos três turnos de atividades. A primeira atividade foi a apresentação do serviço pela coordenadora, que contextualizou e explicitou a estratégia, desde sua origem e as principais linhas de ação/intervenção até o fluxo e as estratégias de operacionalização do serviço.

As atividades seguintes foram visitas domiciliares às gestantes e puérperas em situação de vulnerabilidade social que se encontram em acompanhamento pelo serviço. Nessas visitas foi percebida a necessidade e a importância da articulação com os CSF para a efetivação do trabalho do trevo de quatro folhas - de grande auxílio no cuidado dessas famílias em suas condições de vida.

Ressaltamos que experienciar algumas atividades desenvolvidas por esse serviço foi essencial para nossa formação profissional, ao passo que essa estratégia está em constante diálogo com as equipes de Saúde da Família, na atenção integral à mulher/ gestante/puérpera, devendo ser comum à articulação interdisciplinar e ao olhar para a subjetividade.

\section{Centro de Orientação e Apoio Sorológico}

0 SUS tem como um de seus objetivos cuidar integralmente da saúde da população e é sob essa perspectiva que foram desenvolvidas ações voltadas à prevenção e controle das Infecções Sexualmente Transmissiveis (IST) ${ }^{13}$. É nesse contexto que o Coas se insere como equipamento articulado aos demais serviços do SUS para a ampliação do acesso ao diagnóstico das IST, o acompanhamento e a descentralização de ações que compreendam a temática.

Como forma de conhecimento do serviço, distribuímos nossa carga horária de 12 horas entre a observação da estrutura física do espaço, a conversa com a equipe de profissionais, os usuários e os familiares, a compreensão da rotina de trabalho e a 
facilitação de grupo terapêutico. Nesses momentos, observamos a importância de compreender a política que preconiza as ações na área, especialmente como modo de ofertar uma atenção mais qualificada aos usuários que dela necessitam.

De modo semelhante aos outros serviços vivenciados, pudemos notar que o contato com os usuários e familiares se mostrou importante para a compreensão de suas vivências e desafios. 0 perfil do público acompanhado é composto predominantemente por pessoas residentes em outros municípios da região, o que nos aponta as dificuldades enfrentadas semanalmente por esses usuários, que não contam com suporte de qualidade em seus locais de origem.

A facilitação de um grupo terapêutico na Casa de Apoio Rosa Gatorno, uma instituição não governamental ( $O N G$ ) de Sobral que também acolhe os usuários do Coas, constituiu um dos momentos mais potentes desse processo. Ao trabalhar questões vivenciais e proporcionar um espaço de escuta para usuários e familiares, observamos quanto o acompanhamento terapêutico faz diferença no prognóstico da doença e na forma como os usuários soropositivos e seus familiares veem esse aspecto.

\section{Centro de Referência em Saúde do Trabalhador}

0 primeiro contato com o serviço ocorreu em um espaço com todos os residentes, onde foram apresentados seu objetivo e funcionamento. 0 Cerest apresenta como finalidade ampliar a Rede Nacional de Atenção à Saúde dos Trabalhadores (Renast), com vistas a atuar na prevenção dos adoecimentos decorrentes das atividades laborais, bem como nos problemas de acidentes, morte e doenças relacionadas ao trabalho.

0 Cerest de Sobral é caracterizado como 1 dos 7 centros regionais do estado do Ceará, tendo sobre sua área de abrangência 47 municípios, e é composto pelas seguintes coordenadorias regionais de saúde (CRES): Acaraú, Camocim, Crateús e Sobral, contando com equipe multiprofissional.

Durante a vivência, participamos de outros 2 turnos no serviço, sendo que em 1 acompanhamos a psicóloga do serviço em uma atividade de divulgação para estudantes, do fazer e das contribuições do Cerest, com a finalidade de repassar os fluxos do serviço, como e em que casos podem ser adotados os encaminhamentos, a fim de ressaltar sua importância na rede de saúde.

No outro turno de vivência, acompanhamos uma

\section{o Cerest de Sobral é caracterizado como 1 dos 7 centros regionais do estado do Ceará...}

atividade realizada em parceria com o CSF Centro, onde ocorreu a "Saúde no Mercado", que constitui uma atividade mensal de promoção de saúde realizada pelo CSF, no mercado público de Sobral. Nessa atividade foi abordada a temática saúde do trabalhador, por meio de educação em saúde com os funcionários do mercado. Foram abordadas algumas temáticas, como: postura, lesões por esforços repetitivos ou distúrbios osteomusculares relacionados ao trabalho (LER/DORT) e saúde auditiva, visando a levar informação aos trabalhadores e incentivar as práticas laborais saudáveis, objetivando reduzir os riscos ambientais no trabalho.

Sob essa perspectiva, concebemos a atuação do Cerest na rede municipal de saúde de Sobral como fundamental para a saúde dos trabalhadores, pois ele vem realizando atividades que buscam promover a saúde na tentativa de evitar agravos decorrentes das atividades laborais.

\section{CONCLUSÃO}

A experiência vivenciada foi bastante significativa para o processo formativo da residencia multiprofissional, possibilitando desenvolver conhecimento, articulação e diálogo entre diversos serviços, espaços e sujeitos da rede de assistência à saúde de Sobral. Endossamos que esses momentos proporcionaram a construção de vínculos entre profissionais e serviços que, apesar de fazerem parte da mesma rede, ainda apresentam restrições na comunicação por questões burocráticas. Atualmente, constatamos a ampliação do diálogo e vínculo, entre residentes e alguns profissionais e serviços, conseguindo maior articulação e condução do cuidado.

Como limitação percebida durante a vivência de extensão apontamos a atual configuração desse processo no projeto pedagógico da RMSF/EFSFVS, que delimita a realização das vivências apenas nos serviços da rede de saúde, em detrimento de outros 
serviços que compõem as redes intersetoriais. Acreditamos que esse processo deve ser pensado como espaço formativo para além do setor saúde, possibilitando outros diálogos, como preconizado pelas políticas de organização do SUS. Desse modo, concretizamos 0 aspecto $d a$ intersetorialidade enquanto diretriz do sistema de saúde.

A experiência mostrou-se um momento de impacto e estranhamento das múltiplas formas de fazer psicologia. Estranhamentos necessários, pois fazem parte do processo natural de conhecimento dos espaços e práticas a que nos propomos observar. Por vezes, deparamo-nos com atuações que subvertem a lógica eminentemente clínica e superam as circunscrições do tradicional modo de fazer da psicologia, supostamente voltado à atenção individualista. Sob essa perspectiva, mostrou-se possível visualizar contextos amplos de compreensão da psicologia como profissão e que, por isso mesmo, podemos observar diferentes desdobramentos dessa compreensão refletidos nos efeitos e implicações da prática.

$\mathrm{Na}$ vivência de extensão, essas inquietações iniciais serviram de base para a adoção de um específico posicionamento que muito nos auxiliou na problematização das realidades observadas. Percebemos que é necessário repensar a prática da Psicologia refletindo sobre novos e possiveis modos de intervenção, que possibilitem aproximações efetivas com a realidade dos serviços visitados e que, observando especialmente o contexto do SUS, possam contribuir para a promoção da saúde e para a compreensão dos caracteres múltiplos do processo saúde-doença.

Assim, a vivência de extensão constituiu ricos momentos de interrupção de fluxos e recriação de percursos, processos valiosos que possibilitaram repensar questões relativas à prática do psicólogo e observar perspectivas que se desdobram em relação a essa prática. Diferentemente do que poderia se pensar, a finalização desses escritos aponta não para

$$
\text { ...atuações que }
$$

subvertem a lógica eminentemente clinica e superam as circunscrições do tradicional... o término, mas para a continuação de um processo que ainda tem muito a percorrer. Um caminho longo e ao mesmo tempo diferente dos demais: o único que só faz sentido à medida que não tem fim. Ponhamos, então, os pés no chão e o experimentemos...

\section{CONTRIBUIÇÃO DOS AUTORES}

Ana Karina de Sousa Gadelha contribuiu com o delineamento da pesquisa e a estruturação e revisão crítica do manuscrito. Amanda Colares Bezerra, George Luiz Costa e Paulo Cesar de Moura Luz contribuíram com o delineamento e a realização da pesquisa e a redação do manuscrito.

\section{REFERÊNCIAS}

1. Andrade LOM, Barreto ICHC, Martins Júnior T, Amaral MIV, Parreiras PC. Escola de Formação em Saúde da Família Visconde de Sabóia: três anos construindo a tenda invertida e a educação permanente no SUS. Sanare (Sobral, Online) [serial on the internet]. 2004 [cited 2018 May 4];5(1):33-9. Available from: https://sanare.emnuvens.com.br/sanare/ article/view/120/112

2. Martins Júnior T, Parente JRF, Souza FL, Sousa MST. A residência multiprofissional em Saúde da Família de SobralCeará. Sanare (Sobral, Online) [serial on the internet]. 2008 [cited 2018 May 14];7(2):23-30. Available from: https:// sanare.emnuvens.com.br/sanare/article/viewFile/28/23

3. Carvalho AB, Nepomuceno LB. A residência multiprofissional em Saúde da Família potencializando a transformação através da formação: uma utopia necessária. Sanare (Sobral, Online) [serial on the internet]. 2008 [cited 2018 May 14];7(2): 31-7. Available from: https://sanare. emnuvens.com.br/sanare/article/view/29/24

4. Barros MMM, Jorge, MSB. Concepções e práticas de atenção a saúde mental: o discurso do sujeito coletivo. Fortaleza (CE): Ed. UECE; 2011.

5. Quindere PHD, Jorge MSB. (Des)construção do modelo assistencial em saúde mental na composição das práticas e dos serviços. Saúde Soc [serial on the internet]. 2010 [cited 2018 May 14];19(3):569-83. Available from: http://www. scielo.br/pdf/sausoc/v19n3/09.pdf

6. Brasil. Portaria n. 336/GM, de 19 de fevereiro de 2002 [document on the internet]. Brasília (DF): Ministério da Saúde; 2002 [cited 2018 May 14]. Available from: https:// edisciplinas.usp.br/pluginfile.php/4175108/mod resource/ content/1/Portaria\%20GM\%20336-2002.pdf

7. Sá RAR, Barros MMM, Costa MSA. Saúde mental em Sobral-CE: atenção com humanização e inclusão social. Sanare (Sobral, Online) [serial on the internet]. 2007 [cited 2018 May 14];6(2):26-33. Available from: https://sanare. emnuvens.com.br/sanare/article/view/150/142 
8. Souza FSP, Silva CAF, Oliveira EN. Serviço de emergência psiquiátrica em hospital geral: estudo retrospectivo. Rev Esc Enferm USP [serial on the internet]. 2010 [cited 2018 May 14];44(3):796-802. Available from: http://www.scielo.br/ $\mathrm{pdf} / \mathrm{reeusp} / \mathrm{v} 44 \mathrm{n3} / 35 . \mathrm{pdf}$

9. Bezerra Júnior B. Considerações sobre terapêuticas ambulatoriais em saúde mental. In: Tundis AS, Costa NR, organizers. Cidadania e loucura: políticas de saúde mental no Brasil. 7. ed. Petrópolis, RJ: Vozes; 2001. p. 134-169.

10. Amarante P. A (clínica) e a reforma psiquiátrica. In: Amarante $P$, coordinator. Arquivos de saúde mental e atenção psicossocial. Rio de Janeiro: Nau; 2003. p. 45-65.

11. Romagnoli RC, Paulon SM, Amorim AKMA, Dimenstein M. Por uma clínica da resistência: experimentações desinstitucionalizantes em tempos de biopolítica. Interface Comun Saúde Educ [serial on the internet]. 2009 [cited 2018 May 14];13(30):199-207. Available from: http://www. scielo.br/pdf/icse/v13n30/v13n30a16.pdf

12. Sousa FJS, Sucupira ACSL, Aguiar ISM, Mesquita VAL, Sales ENBG. Programa Trevo de Quatro Folhas: uma ação efetiva para a redução da mortalidade infantil em Sobral Ceará. Sanare (Sobral, 0nline) [serial on the internet]. 2012 [cited 2018 May 14];11(1):60-5. Available from: https:// sanare.emnuvens.com.br/sanare/article/view/268/241

13. Brasil. Práticas profissionais dos(as) psicólogos(as) no campo das DST/AIDS. Brasília (DF): Conselho Federal de Psicologia; 2009. $\ldots \ldots \ldots \ldots \ldots \ldots . . . .$.

$\ldots \ldots \ldots \ldots \ldots \ldots \ldots$

${ }^{\circ}$ $\ldots \ldots \ldots \ldots \ldots \ldots \ldots$
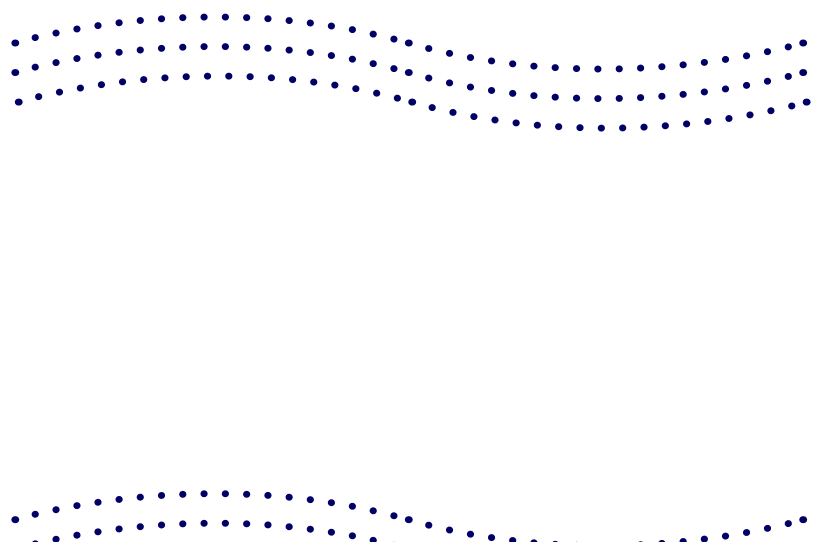

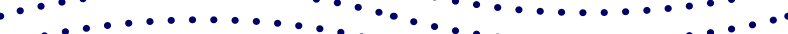

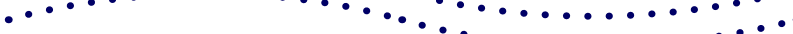
$\cdots \ldots \ldots$
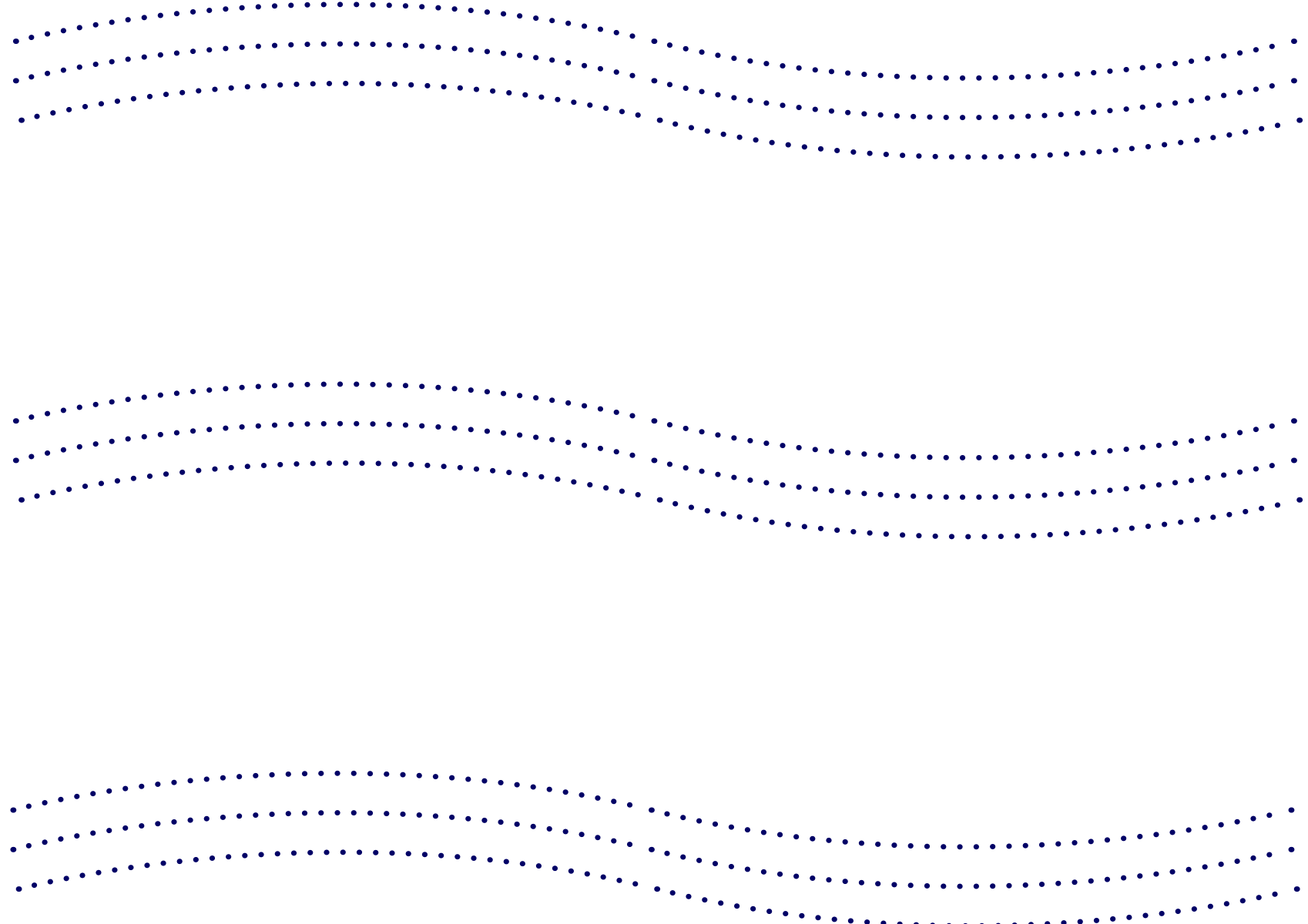